\title{
A EXPANSÃO DAS CIDADES BRASILEIRAS: UM PROCESSO SEM FIM
}

\author{
THE GROWTH OF THE BRAZILIAN CITIES - A NEVER-ENDING PROCESS
}

\section{COSTA, Staël de Alvarenga Pereira}

Arquiteta e urbanista (EAUFMG), master of Arts in Urban Design (Oxford Polytechnic), doutora em Arquitetura e Urbanismo em Estruturas Ambientais Urbanas (FAUUSP), professora da Escola de Arquitetura/ UFMG - Departamento de Urbanismo. E-mail: spcosta@arq.ufmg.br

\section{RESUMO}

As grandes cidades brasileiras apresentam na atualidade processos de desenvolvimento e de formação das suas formas urbanas semelhantes, apesar de algumas terem sido criadas seguindo planos urbanísticos diversos e algumas mesmo, fundadas para atender propósitos políticos diferenciados.

Apesar destas diferenças todas estas ao crescer apresentam expansões além dos limites administrativos territoriais. As políticas de planejamento urbano e controle da expansão urbana provaram-se pouco eficazes na formação de cidades legais e o crescimento extensivo praticamente, ocorre sem controle.

Os novos tipos de ocupação como as atividades industriais, as comerciais de grande porte, novos subúrbios residenciais e, ao mesmo tempo, as periferias pobres apresentam diferentes formas urbanas. Para o abrigo destas formas, as florestas têm suas áreas reduzidas, a paisagem é transformada, os corpos d água são canalizados. No cômputo final os seus leitos são cada vez mais rasos.e polvídos.

Este trabalho apresenta as principais características das cidades que estão sob processos semelhantes e discute o tipo mais recente deste processo, que ocorre nas bordas das cidades. Apresenta como estudo de caso, a cidade de Belo Horizonte, uma cidade planejada para ser uma capital de estado 108 anos atrás, para questionar se as políticas governamentais estão sendo realmente implementadas como normas para controle da expansão urbana ou se são somente utilizadas para ocultar a real intervenção de promover a especulação do solo.

\section{Palavras-chave: Bordas metropolitanas, políticas públicas, impactos.}

\begin{abstract}
Great Brazilian cities are similar in terms of urban forms and development processes, in spite of the fact that some of them were implemented by different development plans and some have been founded to serve different purposes. Despite these differences they have been growing and be experimenting territorial expansion nowadays. Planning processes were implemented in certain areas but few of them proved effective in forming legal cities.

The change occurs in the form of occupation of the unused rural land around these towns, which have been deforested and bulldozed to accommodate new forms of urban settlement.

New settlements such as industrial, commercial areas and new residential suburbs as well as peripheral housing estates assumed different urban forms.

To make all this possible, forests have had their planted area reduced, the landscape suffered change, the rivers have been channeled, and all such actions culminated in erosion, and soil drainage into the rivers. In the aftermath rivers have been made into polluted, shallow channels.

This paper presents the main characteristics of Brazilian cities that are undergoing a similar process. It discusses the most recent of such processes, occurring in the outskirts of cities, and introduces a case study of Belo Horizonte, a city that was planned to be the state capital 108 years ago. One of the reasons is going to be discussed in this paper, which will analyse if the government policies really meant to be used as control development measures or only to mask the real intention of making profit from land expansion.
\end{abstract}

Key words: Metropolitan border outskirts, planning policies, impact. 


\section{O caso de Belo Horizonte - sua criação e o seu desenvolvimento}

\section{Antecedentes}

A criação e o desenvolvimento da cidade de Belo Horizonte foram decorrentes de uma estratégia governamental, ao final do século XIX, que definiu a sua construção, de acordo com um plano urbanístico, que determinou a sua ocupação num planalto situado na área central do Estado de Minas Gerais, destinando-a como sua nova capital'.

A forma urbana da antiga capital, Ouro Preto, refletia soluções urbanísticas e tecidos urbanos semelhantes aos das cidades dos colonizadores portugueses, que estavam sendo repudiados pelos modelos republicanos. A antiga capital fora implantada em relevo acidentado ${ }^{2}$, dificultaria expansões para absorção de uma nova estrutura administrativa para o estado idealizado, no século XIX.

O local onde se situa o planalto de Belo Horizonte é caracterizado pela presença de vales extensos e largos com predominância de médias e baixas declividades, localizado na zona metalúrgica do Estado de Minas Gerais. Estes aspectos foram determinantes para a escolha do local da nova capital $^{3}$ porque havia a intenção de se construir uma cidade moderna e ampla.

Uma comissão foi encarregada de examinar localidades que poderiam ser as escolhidas para abrigar a nova capital. O sítio onde se localizava o "Arraial do Curral Del Rey", foi selecionado. A sua escolha possibilitaria o planejamento de uma nova cidade, com características urbanísticas inteiramente diferentes do povoado ali implantado, sendo este totalmente demolido e, no seu lugar, foi implantada uma urbe estruturada por três zonas de ocupação: a zona urbana, a zona suburbana, e a zona rural - esta destinada à implantação dos sítios hortigranjeiros.

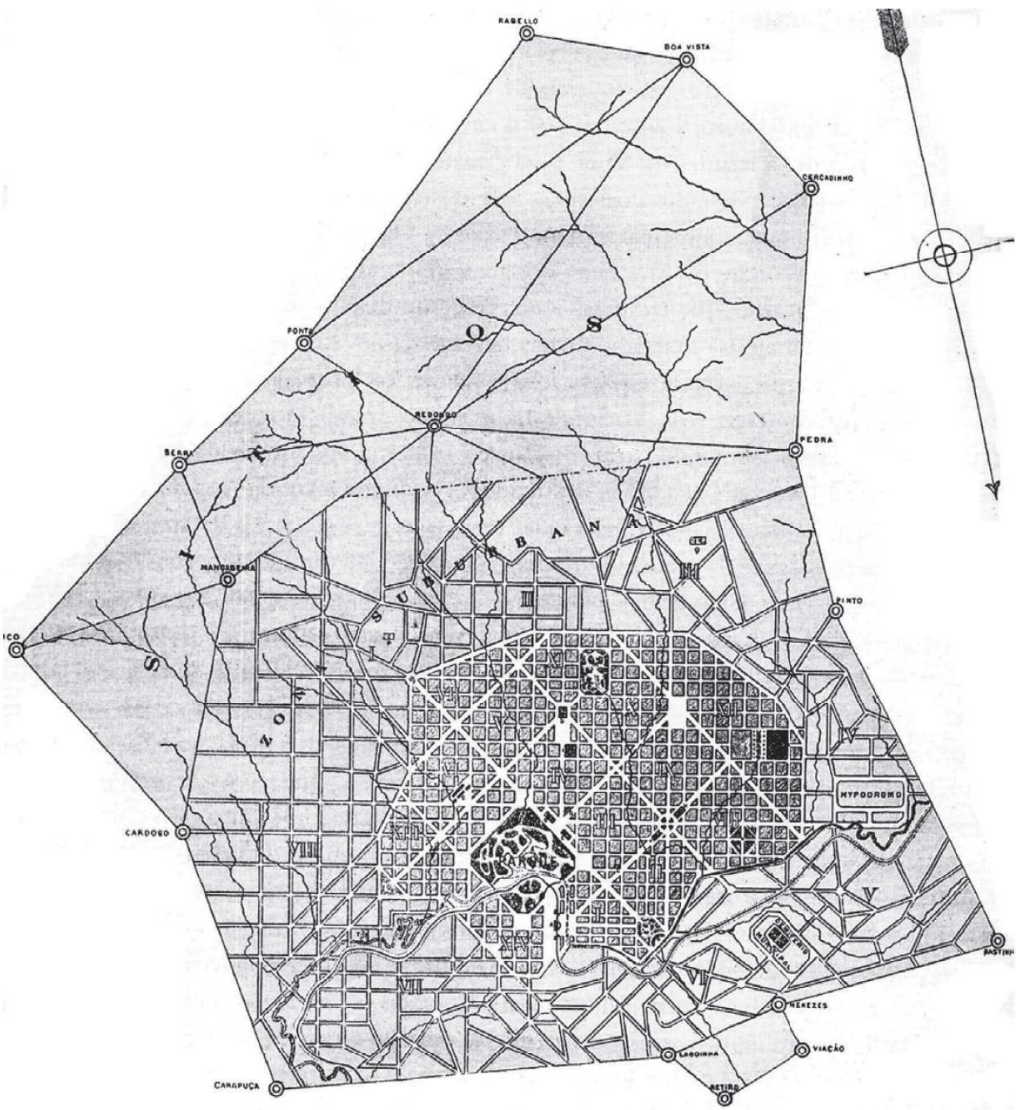

Figura 7: Plano da cidade de Belo Horizonte traçado elaborado pelo engenheiro Aarão Reis para a zona urbana estabelece uma malha ortogonal na forma de quarteirões quadrados, separados por vias largas e avenidas diagonais, implantadas sobre um planalto, em declive. Este traçado ${ }^{4}$ constituído por uma malha rígida considera o relevo como uma planície plana e regulariza todos os cursos dos córregos e ribeirões, efetua cortes, constrói viadutos nos local onde o relevo não permite a implantação do traçado em xadrez ${ }^{5}$.

\section{A evolução da cidade de Belo Horizonte}

A importância da ocupação inicial das zonas planejadas reflete-se no tratamento e detalhamento das partes. A zona urbana é retalhada para a implantação da malha ortogonal composta por quarteirões de 120 metros de comprimento, 
subdivididos em 10 lotes, com testadas mínimas de 12 metros, contidos por ruas de 12 metros de largura. A cada 3.600 metros, os quarteirões são secionados por avenidas diagonais com 18 metros de largura, que se encontravam em largos e praças. Duas largas avenidas com $50 \mathrm{~m}$ de largura subdividem a zona urbana em dois eixos: um implantado seguindo orientação norte/sul e o outro na direção leste/oeste, as quais avenidas se encontram numa praça central, a praça Sete de Setembro. Todo o espaço urbano, por sua vez, estava contido por uma larga avenida perimetral que limitava a zona urbana da zona suburbana.

Desde o início da evolução da cidade de Belo Horizonte houve um embate entre as forças políticas, defensoras do planejamento e da ordenação territorial rígida, e a ocupação espontânea, que surgia induzida pela circulação ferroviária, cujas estações configuravam pólos centralizadores, levando a um crescimento urbano natural, ao seu redor.

Para os defensores do positivismo e do planejamento ${ }^{6}$, a lógica da ocupação e do adensamento na nova capital seria o eixo norte-sul representado pela avenida Afonso Pena. Na zona urbana seriam implantados os edifícios públicos, os equipamentos de apoio à atividade administrativa governamental, os parques, as praças e os bairros destinados ao abrigo dos servidores públicos que foram transferidos de Ouro Preto.

A implantação de um ramal ferroviário no sentido oeste, paralelo ao ribeirão Arrudas, induziu nova tendência de ocupação urbana, que referenciava a antiga ocupação do arraial do Curral Del Rei.

A construção de estações de transbordo, ao longo deste eixo ferroviário foi o vetor que induziu o aparecimento de pequenos núcleos que, gradativamente, foram se consolidando como bairros destinados à residência de população operária, distanciados da área urbana original. Outro fator que contribui para consolidar a ocupação inicial desta área a oeste da cidade seria anos após, a construção de um distrito industrial localizado no limite do município de Belo Horizonte e Contagem.

A consolidação efetiva do distrito industrial iria ocorrer, entretanto, somente no final da década de 1940, após a implantação de infra-estrutura viária urbana, a consolidação da rede de energia elétrica e a implantação de um plano rodoviário. Na década seguinte, a instalação de um importante pólo industrial, a Siderúrgica Mannessman, contribuiu para a configuração industrial da região oeste.

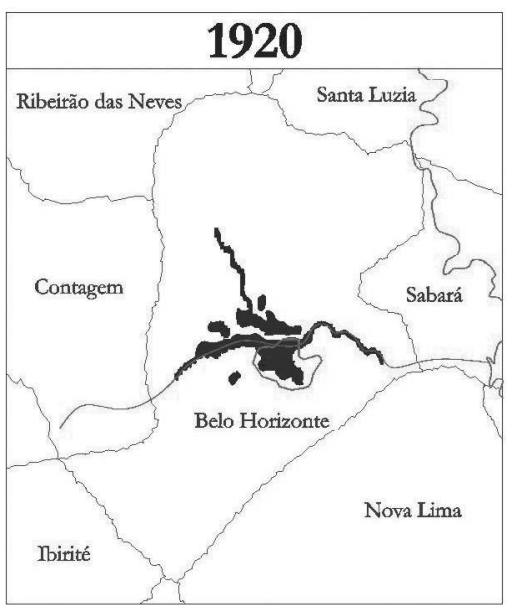

Figura 2

Evolução do aglomerado urbano 1920

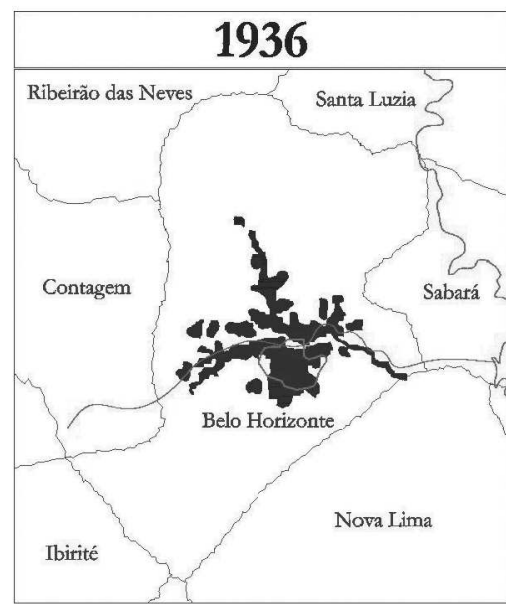

Figura 3

Evolução do aglomerado urbano 1936

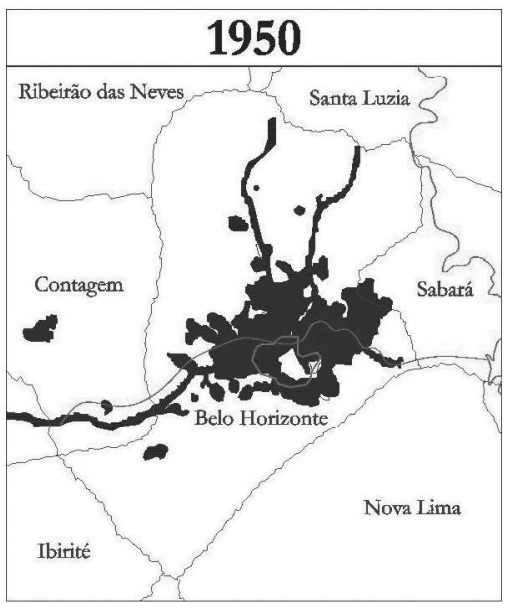

Figura 4

Evolução do aglomerado urbano 1950 
Tais medidas transformariam a capital do estado num pólo irradiador e centralizador desta rede rodoviária e resultariam no processo de concentração espacial e levaram a um crescimento superior ao de outras regiões, concentrando cerca de $45 \%$ da população urbana do estado ${ }^{7}$.

\section{A região metropolitana de Belo Horizonte $(\mathrm{RMBH})$ e a evolução do aglomerado metropolitano}

A criação $0^{8}$ da Região Metropolitana de Belo Horizonte (RMBH) ocorreu em 1973, conseqüente ao crescimento da cidade de Belo Horizonte que se acentuou a partir da década de 1950 e que levou à formação de um aglomerado composto por territórios municipais submetidos a diversas jurisdições administrativas.

Neste período, o centro de comércio de Belo Horizonte estava consolidado como o centro principal de negócios, comércio e prestação de serviços na zona urbana e vários empreendimentos são implantados, principalmente ao longo das largas avenidas e nas áreas industriais conectando o centro da cidade aos eixos rodoviários.

A conurbação dos municípios na área oeste iria configurar a Aglomeração Metropolitana de Belo Horizonte e estimular a implantação de grandes novos empreendimentos industriais naquele vetor de expansão. Outros significativos complexos industriais como a Refinaria Gabriel Passos, da PETROBRAS, e a Fábrica de Automóveis FIAT vão ser construídos próximos ao Distrito Industrial Juventino Dias e à Siderúrgica Mannessman. Com isto, Inúmeras indústrias de apoio àquelas seriam atraídas para o local e trazem consigo a ocupação residencial, o que consagra o setor oeste como o de maior tendência da ocupação metropolitana.

A RMBH compreendia onze municípios 9 e ocupava uma área de $3,670 \mathrm{~km}$ quadrados e se expandia tanto na direção oeste quanto a direção norte. Esta mancha de ocupação contínua perfazia 11,8\% da superfície total do território metropolitano, no início dos anos de 1970.

Outra frente de expansão se inicia na região norte de Belo Horizonte e compreendia a ocupação decorrente da implantação do complexo urbanístico da Pampulha na década de 1940 e a construção de um eixo viário que teria a função estrutural de unir a área central à região norte de Belo Horizonte.

A implantação de pequenas áreas industriais que utilizam o potencial minerário da região calcária nos distritos industriais de Santa Luzia contribui para consolidar a expansão da cidade na região norte, após os anos de 1950.

Nos anos de 1970, a implantação de indústrias de beneficiamento de calcário e de cimento nos municípios na área norte da e a construção da via expressa norte-sul, ligação Belo HorizontePedro Leopoldo, vão impulsionar uma nova ocupação na direção norte, por população de classe média e classe média baixa.

\section{A evolução da RMBH pós 1970}

A construção de inúmeros conjuntos habitacionais de baixa renda próximos à via expressa norte-sul consolida esta segunda frente de expansão, permeada por uma ocupação residencial e industrial nas bordas, em 1980. A implantação do Aeroporto de Confins, na mesma época contribui para a expansão da mancha urbana da aglomeração e sua conurbação com bairros localizados nas bordas norte do município de Belo Horizonte.

Outro vetor de expansão da mancha da aglomeração de Belo Horizonte define-se na direção sudoeste, espalhando-se sob a forma de bairros populares de baixa renda, sobre áreas periféricas do município de lbirité e, a leste, o processo se repete sobre o município de Sabará. 
Em 1987, a lei complementar $n .^{\circ} 48$ de 12/11/ 1987 incorpora os outros tantos municípios ${ }^{10}$ ao perímetro original da $\mathrm{RMBH}$. Todos estes integram o novo perímetro da $\mathrm{RMBH}$ que vai abrigar 3.812888 pessoas numa superfície territorial de 6.246, $63 \mathrm{~km}$ quadrados.

A expansão contínua leva a forma urbana da capital a se expandir além dos limites territoriais administrativos e a se conurbar com outras cidades, principalmente ao oeste, ao norte e a noroeste. Como conseqüência, as industrias se deslocam do centro da cidade na direção deste eixo deixando diversas edificações e lotes abandonados.

A análise da expansão atual da mancha urbana demonstra que esta continua a se deslocar para a direção oeste. Grande parcela da população carente ${ }^{11}$ expulsa de Belo Horizonte se fixou nas bordas dos municípios limítrofes, a noroeste e essa ocupação, bifurca-se para a direção nordeste, vindo a caracterizar o mais recente vetor de ocupação de classe pobre da RMBH (2004).

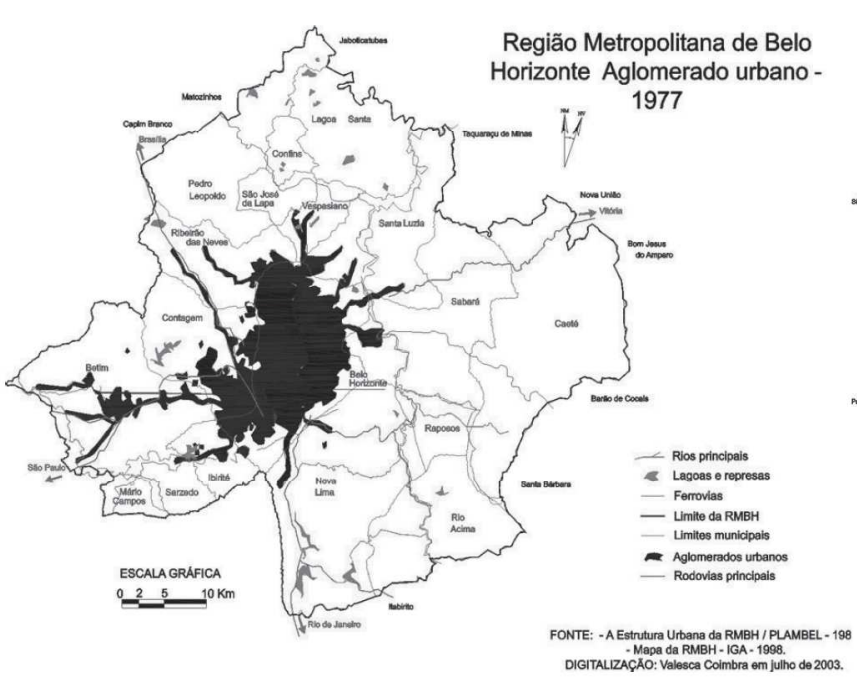

Figura 5: $\mathrm{RMBH}-1970$

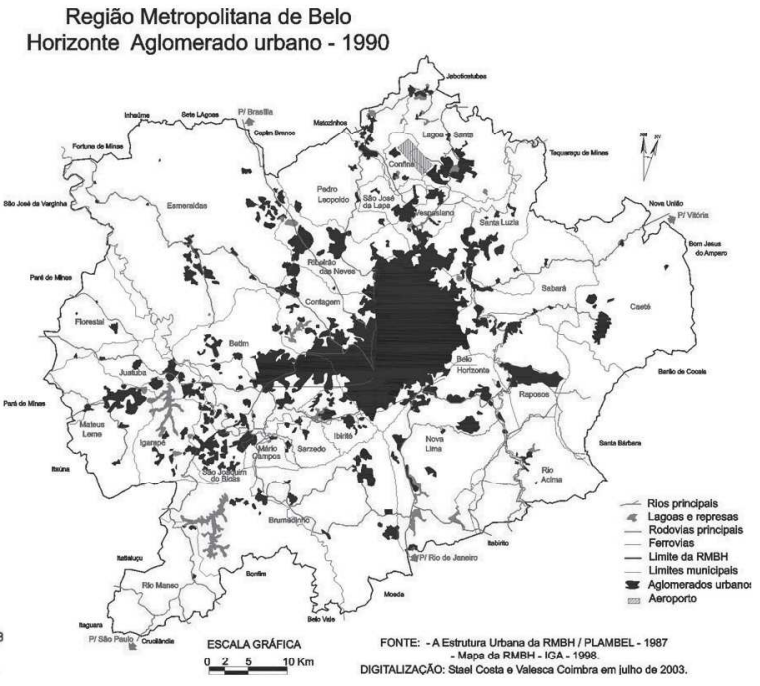

Figura 6: $\mathrm{RMBH}-1990$

\section{A deterioração do centro de Belo Horizonte e sua transformação em centro de serviços metropolitanos}

A mudança do comércio varejista para bairros pericentrais ${ }^{12}$ é outra conseqüência da expansão da cidade. Na região sul da cidade de Belo Horizonte esta expansão se inicia desde os anos de 1960, quando o centro tradicional da área de comércio perde o poder de atração do varejo e da classe média alta que se desloca do Bairro dos Funcionários.

É nesta época que ocorre a expansão deste para os bairros pericentrais, com alguns se consolidando como subcentros ato que ocorre, principalmente, na zona sul da capital.

Esta ocupação de comércio varejista em bairro residencial provoca a mudança ${ }^{13}$ de setores da classe média alta para bairros residenciais unifamiliares, nas áreas mais distantes do setor sul.

A população de alta renda, ao abandonar o uso do centro tradicional como área de comércio e de residência, iria contribuir para a sua apropriação por grande parcela de população de baixa renda e consolidar a sua função como centro de serviços da RMBH. A conseqüência desta inovação é a mudança da ocupação residencial unifamiliar para estas áreas limítrofes, muito próximas à capital do estado, por sua beleza cênica e pelo clima de montanhas, o que atrai também os incorporadores, para o parcelamento das terras seja para residências, para segunda moradia ou para sítios de recreio ${ }^{14}$. 
Para Villaça ${ }^{15}$, o estabelecimento do comércio ambulante e do setor de serviços, na área central torna-se o fator de expulsão da atividade residencial para outras áreas da cidade. Ele também expõe que, a área central vai sendo apropriada pela classe mais pobre, que não demanda melhorias nos equipamentos públicos e melhorias ambientais e a municipalidade desvia os recursos que ai seriam alocados, para outras áreas.

Assim ocorre a decadência da área central. De qualquer forma, as qualidades excepcionais da área central tais como acessibilidade, a provisão de infra-estrutura, as condições topográficas, edificações sólidas e de valor arquitetônico irão certamente, condicionar programas de revitalização e requalificação urbana ${ }^{16}$, algum dia, espera-se.

Se a principal cidade da aglomeração metropolitana tornou-se o principal centro prestador de serviços e de entretenimento, outras funções serão destinadas aos municípios vizinhos.

Em 2004 há municípios que exercem as funções de apoio à atividade metropolitana, tais como os denominados cidades-dormitório. Nos municípios a sudoeste concentra-se a produção de hortigranjeiros e a produção de frutas, outros tantos municípios são reservados à produção de insumos. Em outros se localizam as principais captações de água para os reservatórios que abastecem a $\mathrm{RMBH}$.

As áreas de lazer metropolitano localizam-se também nos municípios ao norte e a sul da mesma região.

As cidades conurbadas repetem funções que foram uma vez planejadas para ocorrer nas zonas suburbanas e rurais determinados no plano original da criação da cidade de Belo Horizonte. O fato que se observa é que, não obstante os ideais da sua criação, das determinações contidas nas normas e planos urbanísticos; Belo Horizonte aos 108 anos de idade torna-se a terceira cidade do país em população e apresenta problemas semelhantes a uma típica metrópole de um país em desenvolvimento.

\section{As políticas e ações governamentais recentes - uma política moderna, ou uma política tradicional?}

A tendência mundial que consiste em de requalificar os tecidos urbanos dos centros das cidades para implementar um projeto de revitalização urbana deveria ser um instrumento típico de política urbana, mas lastimavelmente, isto não ocorre em Belo Horizonte e, na verdade, pouco disto ocorreu nesta cidade. Observa-se pelo contrário, uma atitude recorrente dos governantes tanto municipais quanto estaduais - a de se implementar estratégias, sob o argumento de que estes lugares serão valorizados ao longo do tempo. Entretanto, o que tem ocorrido é a efetivação de propostas que geralmente, levam "a deterioração de áreas previamente ocupadas", a expansão da cidade, e conseqüentemente a destruição da paisagem.

O mais recente exemplo desta prática está se em curso na Praça da Liberdade.

O Governador de Minas Gerais seguindo decisões também empreendidas pelo seu antecessor, decidiu mudar o Centro Administrativo do Estado e construir um novo centro administrativo numa área distante, livre, num aeroporto privado.

Grande reação popular ocorre após esta decisão, tanto quanto a mudança do centro administrativo quanto da ocupação da área do aeroporto. Das muitas preocupações a que mais se destaca é a que se refere ao acesso ao local, pois o aeroporto está situado numa área residencial de classe média, que possui como acesso principal, uma única via coletora de porte médio.

A crítica se fundamenta no incremento do tráfego que provoca congestionamentos, o que demanda desapropriações para alargamento da via de acesso ao novo centro administrativo. 
Ao mesmo tempo, Oscar Niemeyer elabora o projeto do novo centro administrativo, mas as dificuldades, principalmente as relacionadas ao acesso e aos empecilhos legais impedem que esta decisão se concretize.

Por outro lado, uma nova área é escolhida, adjacente ao novo complexo viário que faz a ligação entre a cidade de Belo Horizonte e o aeroporto de Confins. A antiga rodovia de acesso, Belo Horizonte ao aeroporto de Confins está em reformas, sendo ampliada para receber novas pistas, viadutos acessos e tratamento paisagístico, denominada "Linha Verde" Para a consolidação desta nova frente de expansão, uma das áreas adjacentes está destinada a abrigar o novo centro administrativo do Estado de Minas Gerais. Com este virão invariavelmente, os equipamentos de apoio, novos condomínios residenciais, novos acessos e a valorização da terra.

Por outro lado, o centro administrativo original possui a acessibilidade, como uma das suas maiores qualidades e a praça da Liberdade situada no seu interior é um lugar intensamente utilizado pela população todas as horas do dia.

atual centro administrativo é composto por nove edifícios ecléticos ocupados pelas secretarias de estado e o Palácio da Liberdade, sede do governo estadual.

projeto pretende transformar os nove edifícios num centro cultural e as edificações em sede de orquestras e grupos teatrais. Todas estas decisões vão invariavelmente levar a um incremento de tráfego para a região, teme-se pelos congestionamentos e pela superocupação da praça, o que pode causar a sua deterioração.

Outro aspecto pouco considerado neste projeto relaciona-se ao desconhecimento dos riscos no sitio natural, que na época da construção da cidade foi terraplenado e aterrado para se elevar a cota do centro administrativo para que este se distinguisse na paisagem, como um ponto focal de várias avenidas. Outras formas de acesso ao local estão sendo projetadas bem como a provisão de estacionamentos, todos subterrâneos. Finalmente questiona-se a superocupação de edifícios estruturados para outras funções que deverão abrigar sobrecargas sobre este tipo de solo ${ }^{17}$.

Esta decisão governamental assemelha-se à construção da Pampulha ${ }^{18}$ que naquela ocasião, foi pouco confrontada pela população, mas cuja ocupação não ocorreu da forma planejada pelos governantes.

Vários questionamentos seguem-se a esta decisão e o principal diz respeito à mudança de lugar especialmente construído para ser o centro administrativo do Estado de Minas Gerais e o símbolo da cidade de Belo Horizonte.

Para Lefebvre ${ }^{19}$ estas decisões tem como objetivo deteriorar espaços públicos de grande significação locacional e intencionalmente, enfraquecer a vida urbana. Este autor argumenta que - poder público investe na depreciação e deterioração dos símbolos e dos elementos que contribuem para a manutenção do grupo social, para manipular a interpretação e o vínculo estabelecido entre o usuários e o lugar.

No caso em análise, os dois governadores sistematicamente têm investido na transformação do lugar, o mesmo que simboliza a construção da nova capital do estado.

Ao depreciar o centro administrativo e a praça da Liberdade deliberadamente implantados no local mais proeminente da zona urbana da nova capital, acessado pela antiga avenida da Liberdade o poder público pretende enfraquecer o símbolo da nova capital, o seu aparato administrativo e a sua conotação com a liberdade. 


\section{Conclusões}

Este trabalho discute algumas práticas governamentais e os planos urbanísticos da cidade de Belo Horizonte, concluindo estas que tem provocado diversas conseqüências no espaço urbano.

Um deles diz respeito, ao controle da expansão urbana ao promover no centro da cidade atrativos legais fiscais e de uso que contribuem para que a forma urbana se mantenha dentro dos limites originais.

A outra atitude diz respeito aos empreendimentos que condicionam a expansão urbana, pela implantação de vetores e eixos que levam à ocupação de novas áreas.

Este trabalho analisou atitudes governamentais para questionar se houve a intenção de se controlar a expansão ou se, a intenção real foi sempre a de especular terrenos por meio da expansão urbana. Conclui-se que ambas atitudes ocorrem simultaneamente.

Outra constatação que se faz é que autoridades utilizam o conceito de modernidade como um pretexto empregado em vários momentos da evolução desta cidade, mas na realidade este argumento é utilizado na promoção de políticas expansionistas que culminam com a apropriação de novas áreas livres.

que resulta disto tudo é que este desequilíbrio contínuo entre a manutenção do tecido urbano existente para preservação ou deteriorá-lo com novos usos para contribuir para sua futura substituição. O resultado deste conflito pode ser observado nos tecidos urbanos que são continuamente sendo deteriorados e substituídos.

Outra conclusão é sobre a participação pública que ocorre somente na forma reativa sobre a ocupação ou não de um lugar e isto evidentemente, não se caracteriza como uma participação consciente e real. Como o conhecimento e recursos econômicos não são distribuídos de forma equânime para a comunidade, a participação popular não é uma prática efetiva e isto resulta em muita acomodação e aceitação de todo tipo de interferência na forma urbana. Tudo isto pode ser observado na paisagem das cidades cujo tecido urbano e nas edificações pontilhadas de diversos estilos arquitetônicos e de diversas leis de uso e ocupação do solo.

Estes produtos estão presentes também, nas formas de ocupação nas bordas das metrópoles ${ }^{20}$, resultantes do crescimento das grandes cidades, típicos produtos brasileiros do inicio do século XXI. Os efeitos nocivos deste crescimento podem ser observados nas novas formas urbanas, utilizadas para a promoção do lucro, para a exploração e espoliação da paisagem, o que invariavelmente contribui para a riqueza de poucos e a pobreza de muitos principalmente, da paisagem. Até quando?

\section{Notas}

(1) BARRETO, Abílio. Belo Horizonte: Memória histórica e descritiva, história antiga. 1996, p. 345.

(2) BOLTSHAUSER. Noções sobre a evolução urbana nas Américas. 1968, p. 12.

(3) A mudança da nova capital ocorreu durante a implantação da Primeira República e Goulart Reis (1996) consideraa o maior feito da nova modalidade administrativa que se inicia no país. GOULART, Reis. Notas sobre o urbanismo no Brasil. 1997, p. 13.

(4) Esta era fundamentada nos ideais positivistas, que apregoavam o domínio de técnicas e da ordem sobre a natureza. Estas normas, ao se vincularem ao Urbanismo, se expressam pelo uso da medida, da retificação, da ordem e das figuras geométricas, resultando na implantação de traçados urbanos semelhantes à rede, à malha, ao xadrez. PLAMBEL. A estrutura urbana da Região Metropolitana de Belo Horizonte. 1987, p. 46.

(5) BARBOSA. Notas sobre o sítio e posição de Belo Horizonte. 1967, p. 17. 
(6) ANDRADE et al. Belo Horizonte: Um espaço para a república. 1999, p. 28.

(7) MONTE-MÓR. Urbanização e industrialização em Minas Gerais, 1998.

(8) A Lei Estadual. n. 6. 303 de 1974 criou os Conselhos Deliberativos e Consultivos da RMBH e o órgão de gestão metropolitana, a autarquia PLAMBEL.

(9) Betim, Caeté, Contagem, Ibirité, Lagoa Santa, Nova Lima, Pedro Leopoldo, Raposos, Ribeirão das Neves, Rio Acima, Sabará, Santa Luzia e Vespasiano. PLAMBEL. A estrutura urbana da Região Metropolitana de Belo Horizonte. 1987, p. 16.

(10) Capim Branco, Taquaraçu de Minas, Nova União, Baldim, Brumadinho, Florestal, Itaguara, Jaboticatubas, Juatuba, São Joaquim de Bicas, Igarapé, Mateus Leme, Rio Manso e Esmeraldas e também, os novos municípios emancipados Sarzedo e Mario Campos, na região oeste, e Confins e São José da Lapa, ao norte. Elaboração: Fundação João Pinheiro (FJP), Centro de Estatística e Informações (CEI).

(11) SOUSA. Alternativas públicas não estatais para a provisão da habitação popular: O caso do bairro Metropolitano em Ribeirão das Neves. 2002, p.41.

(12) TEIXEIRA: Bairros pericentrais são "aqueles que envolvem o centro urbano determinados pelo uso tipicamente residencial, possuem uma identidade incontestável e, geralmente, se entendem até a periferia. Por ser uma área de transição do núcleo urbano básico, esses bairros raramente são considerados nos estudos urbanísticos". In: Evolução e percepção do ambiente em um bairro pericentral de Belo Horizonte - A Floresta. 1996.

(13) TEIXEIRA: A mudança que ocorre em relação às atividades típicas da antiga zona urbana de Belo Horizonte repete-se em relação à zona suburbana, com a incorporação dos espaços pericentrais ocorrendo em relação às zonas rurais do município, pois as áreas periféricas expandem-se na direção de determinados vetores e conurbam-se com as áreas urbanas de outros municípios, apud.

(14) Ao redor do núcleo há uma zona pericentral integrada ao funcionamento do sistema e que representa um lugar de expansão do centro da cidade. AMORIM FILHO. In: O contexto teórico do desenvolvimento dos estudos humanísticos e perceptivos da geografia. 1987, p. 2-20.

MACEDO. Paisagem, urbanização e litoral: do Éden à cidade.1998. p 34

(15) Outra manifestação da importância dada ao centro pelas camadas de mais alta renda comprovada apenas para as metrópoles brasileiras, talvez as latinas americanas em geral consiste no fato de levarem o centro a se deslocar em sua direção, de maneira que, mesmo quando se afastam dele, esse afastamento seja em parte neutralizado pelo próprio centro na direção delas. Em todas as metrópoles aqui estudadas, sem exceção "os novos centros" que surgiram a partir da década de 1960 (SAVASSI) em Belo Horizonte, imediações do Iguatemi em Salvador; região Paulista, Faria Lima em São Paulo; Boa Viagem no Recife seguiram o caminhamento dos bairros residências das camadas de alta renda. Tão logo o capitalismo se impôs, impôs-se também o mecanismo do mercado e a redução do poder do estado produtor direto do espaço urbano. O Estado passou a ser produtor indireto com a legislação urbanística que, supostamente regularia a iniciativa privada.

(16) PEREIRA COSTA, Stael. Urban reneawl - urban revolution?

(17) Sobre estes questionamentos vide parecer do consultor do IAB/MG. no site www.iab.mg.

(18) PEREIRA COSTA. Naquela ocasião, as reações ocorreram pela não-adesão pela classe média alta a ocupação da área. Transformações, conflitos, perdas e permanências na paisagem sul metropolitana de Belo Horizonte, p. 46.

(19) O direito a cidade, 1969, p. 153.

(20) PEREIRA COSTA. As responsabilidades públicas e civis no planejamento da paisagem, n. 2, 2001.

\section{Bibliografia}

AMORIM FILHO, Oswaldo B. O contexto teórico do desenvolvimento dos estudos humanísticos e perceptivos da Geografia. In: Percepção ambiental: contexto teórico e aplicações do tema. Publicação Especial, n. 5, Belo Horizonte: |GC/ UFMG, 1987.

ANDRADE, Rodrigo Ferreira; MAGALHÃES, Beatriz de Almeida. Belo Horizonte: Um espaço para a república. Belo Horizonte: UFMG, 1989.

BARBOSA, Getúlio Vargas. Notas sobre o sítio e posição de Belo Horizonte. Revista da UFMG, Belo Horizonte, v. 17, n. 1, p. 9-28, 1967.

BARRETO, Abílio. Belo Horizonte, memória histórica e descritiva; história antiga e história média. 2. ed. Belo Horizonte: Fundação João Pinheiro, Centro de Estudos Históricos e Culturais, 1996.

BOLTSHAUSER, João. Noções de evolução urbana nas Américas. 2. ed. Belo Horizonte: Escola de Arquitetura da Universidade de Minas Gerais, v. 1, 2 e 3, 1968. 
GOULART REIS, Nestor. Quadro da arquitetura no Brasil. 1. ed. São Paulo: Perspectiva, 1970. p. 58, jul./ago. 1995.

Notas sobre o urbanismo no Brasil: primeira parte período colonial. Cadernos LAP, São Paulo, n. 8,

MACEDO, Silvio Soares. Paisagem, urbanização e litoral: do Éden à cidade. 1998. Tese (Livre-docência) - Faculdade de Arquitetura e Urbanismo, Universidade de São Paulo, São Paulo, 1998.

MONTE-MÓR. Urbanização e industrialização em Minas Gerais, 1998. Mimeo.

PLAMBEL - Superintendência de Desenvolvimento da Região Metropolitana de Belo Horizonte. A Estrutura Urbana da Região Metropolitana de Belo Horizonte. Belo Horizonte: Secretaria do Estado do Planejamento e Coordenação Geral, v. 1, 1986.

PEREIRA COSTA, Staël Alvarenga. As responsabilidades públicas e civis no planejamento da transformação da paisagem. Rio Claro: Olam Ciência \& Tecnologia, ano I, v. 1, n. 2, nov. 2001. (CD-ROOM).

- Transformações, conflitos, perdas e permanências na paisagem sul metropolitana de Belo Horizonte. 2004. Tese (Doutorado) - Faculdade de Arquitetura e Urbanismo, Universidade de São Paulo, São Paulo, 2004.

SOUSA, Elieth Amélia de. Alternativas públicas não estatais para a provisão da habitação popular: $O$ caso do bairro metropolitano em Ribeirão das Neves. 2002. Dissertação (Mestrado em Sociologia) n. 213. - Faculdade de Ciências Sociais e Gestão das Cidades, PUC Minas. Belo Horizonte, 2001.

TEIXEIRA, M.C V. Evolução e percepção do ambiente em um bairro pericentral de Belo Horizonte. A floresta. 1996. Dissertação (Mestrado em Geografia) - Instituto de Geociências, Universidade Federal de Minas Gerais, Belo Horizonte, 1996.

VILLAÇA, Flávio. Espaço intra-urbano no Brasil. São Paulo: Edusp, 1998. 